\title{
CARIES PREVALENCE IN CHRONIC ALCOHOLICS AND THE RELATIONSHIP TO SALIVARY FLOW RATE AND PH
}

\author{
Walter Dukić1, Tanja Trivanović Dobrijević2 ${ }^{2}$ Marina Katunarić1, Stjepanka Lešić \\ ${ }^{1} S$ chool of Dental Medicine, University of Zagreb, Zagreb, Croatia \\ ${ }^{2}$ Health Centre Novo Mesto, Novo Mesto, Slovenija \\ ${ }^{3}$ Health Centre Županja, Županja, Dental dispensary Štitar, Štitar, Croatia
}

\begin{abstract}
SUMMARY
Aim: The aim of this study was to investigate the dental status of alcoholics; to evaluate the relationship of unstimulated and stimulated saliva $\mathrm{pH}$ on their decayed/missing/filled teeth (DMFT); and to evaluate the relationship of unstimulated and stimulated salivary flow rate on their DMFT.

Method: A cross-sectional study was conducted in patients treated for alcohol dependency ( $n=70$; mean age 41.7 years) and a control group of non-alcoholics ( $n=70$; mean age 39.1 years). Examinations for dental caries were conducted using the World Health Organization (WHO) criteria and questionnaires. The correlation between nominal variables was determined using $x^{2}$ test $(\alpha=0.05)$. The correlation between interval variables was determined using Pearson's correlation coefficient.

Result: The mean DMFT was similar in alcoholics (14.40) and the control group (13.44) ( $p>0.05)$. There was a statistically significant correlation between alcoholism and unstimulated salivary flow rate $(p<0.05)$, but no relationship on DMFT was recorded. No statistically significant differences were found between alcoholics and controls in terms of stimulated salivary flow rate $(p>0.05)$ or stimulated salivary flow on DMFT ( $p>0.05)$. There was a statistically significant correlation between alcoholism and the $\mathrm{pH}$ value of stimulated saliva $(p<0.01)$. There was no correlation between the amount of alcohol consumed and the number of carious lesions ( $p>0.05)$.

Conclusions: No major differences were found with respect to overall DMFT in alcoholics compared to the control group. Alcoholism and stimulated salivary flow rate showed no correlation. Unstimulated salivary flow rate as well as the $\mathrm{pH}$ values of both unstimulated and stimulated saliva, were lower in the alcoholic group.
\end{abstract}

Key words: alcoholism, dental caries, ethanol, hydrogen ion concentration, saliva

Address for correspondence: W. Dukić, School of Dental Medicine, Gundulićeva 5, Zagreb, 01/4802102, Croatia. E-mail: dukic@sfzg.hr

\section{INTRODUCTION}

Alcohol dependency is a condition characterized by psychological, physiological, and pathological changes, all of which are directly relevant to dentistry (1). The psychological effects and the personality changes in the abuser may affect the patient/ dentist relationship, as alcoholics take a reduced interest in seeking and paying for dental care. The physiological effect of alcohol intoxication may lead to the inability to understand and accept advice given by healthcare workers, which in turn results in non-compliance (1). Oral health neglect is a common feature of psychoactive substance (alcohol) abuse (2-4). Contrary to expectations, some reports indicate that alcohol may have a protective role. Alcohol has been thought to influence dental caries via the microbial oxidation of ethanol in saliva in alcohol abusers. The oxidation of ethanol in saliva results in the formation of acetaldehyde, which inhibits the growth of cariogenic oral flora $(5,6)$.

Warnakulasuriya et al. showed that certain alcoholic beverages available in the UK contain high levels of fluoride. This means that anyone who consumes 3 cans of beer a day in the UK would receive the recommended daily upper limit of fluoride through beer alone (7). As most alcoholics may consume more than 3 cans, their exposure to higher levels of fluoride via alcoholic beverages may reduce their caries susceptibility. Alcoholic beverages may also enhance fluoride release from restorative materials such as compomers (8).

A report on alcohol-dependent patients in Denmark in 1996 indicated that alcohol abuse does not directly lead to an increase in dental caries. The authors found that any possible increase in dental caries might be attributed to poorer social status and oral hygiene rather than long-term alcohol consumption (9). Radiological evidence suggests that dental health in individuals dependent on alcohol is characterized by more caries, more horizontal bone loss, and an increased number of vertical infrabony pockets compared to the levels observed in social drinkers (10). Salivary flow is considered to have a caries-preventive effect by influencing the rate of microbial clearance: the higher the flow rate, the faster is the clearance rate (11). The effects of chronic alcohol consumption on saliva secretion or salivary composition are not yet fully understood $(11,12)$. Moderate ingestion of ethanol stimulates the flow of saliva from the parotid gland (13), whereas acute alcohol consumption reduces the rate of salivary flow (14).

The aims of this study were to: 1) establish the decayed/missing/filled teeth (DMFT) value in a group of institutionalized chronic alcoholics and non-alcoholics; 2) evaluate the relationship 
of the unstimulated and stimulated saliva $\mathrm{pH}$ value on DMFT in alcoholics; and 3) evaluate the relationship of unstimulated and stimulated salivary flow rate on DMFT in alcoholics.

\section{MATERIALS AND METHODS}

\section{Study Population}

A cross-sectional study was conducted in a group of 140 subjects, 70 of whom were assigned to the test group (alcoholics) and 70 to the control group (demographic data are given in Table 1). The subjects from both groups were aged from 26 to 51 years. The study was approved by the Ethical committee of the Ormož Psychiatric Hospital, and informed consent was obtained from each study participant. The subjects from the test group were treated for alcohol dependency (as defined by the ICD-10 classification of mental and behavioural disorders) at the Ormož Psychiatric Hospital Addiction Ward, in the Republic of Slovenia. An equal number of matched control subjects who did not consume alcohol and whose medical histories did not indicate alcohol dependence were recruited from a public health dental practice as controls.

The data was gathered via clinical examination, and each participant was given a questionnaire to complete. The questionnaire was used to record standard demographic data (name, surname, age, profession), medical history regarding general health, the type of alcohol beverage typically consumed (beer, wine, or spirit), frequency, duration of use, and smoking habits. The oral examinations took approximately $15 \mathrm{~min}$, and the questionnaire took about $20 \mathrm{~min}$ on average.

\section{Clinical Examination}

Using a feasibility-sampling scheme, all newly admitted subjects in residence or in attendance on the day of the visit were approached and invited to a dental and oral examination. The examinations were performed in accordance with the standard World Health Organization protocol for dental caries examination and categorization (15). All teeth examined were included in calculation of the DMFT index. A masked, experienced dental practitioner conducted a clinical examination by using an explorer and a dental mirror under standard dental operating lights (T.T.D.). All teeth were examined in the same order for each patient. A total of 15 patients were scored twice on separate occasions to test reproducibility and agreement between the scores. The intraclass correlation coefficient was 0.93 .

\section{Establishing and Registering Salivary Status}

Salivary status was established by measuring the flow rates and $\mathrm{pH}$ levels of unstimulated and stimulated saliva. The unstimulated salivary flow rate was obtained by measuring the participants' expectoration into a graduated test tube through a glass funnel. The sample's $\mathrm{pH}$ level was then determined using a colorimetric method that involves the use of $\mathrm{pH}$ Indicator Paper (Merck $\mathrm{KGaA}$, Darmstadt, Germany). The stimulated salivary flow rate was determined by asking participants to chew $1.5 \mathrm{~g}$ of pure wax warmed up to approximately $50^{\circ} \mathrm{C}$. The saliva expectorated was gathered into a graduated test tube. After 5 min of this exercise, the $\mathrm{pH}$ level of the stimulated saliva was immediately determined using the colorimetric method, followed by an evaluation of the salivary flow rate. It is important to immediately determine the $\mathrm{pH}$ level of the stimulated saliva because exposure to air quickly

Table 1. Demographic, behavioural and DMFT characteristics of the study subjects

\begin{tabular}{|l|c|c|}
\hline & $\begin{array}{c}\text { Alcoholics } \\
(\mathrm{N}=70)\end{array}$ & $\begin{array}{c}\text { Control } \\
\text { (N = 70) }\end{array}$ \\
\hline Age (SD) & $41.7(9.26)$ & $39.1(8.78)$ \\
\hline Age 25-30 & $4(5.7 \%)$ & $16(22.8 \%)$ \\
\hline Age 31-36 & $14(20 \%)$ & $25(35.7 \%)$ \\
\hline Age 37-42 & $29(41.4 \%)$ & $20(28.5 \%)$ \\
\hline Age 43-51 & $23(32.8 \%)$ & $55(78.6 \%)$ \\
\hline Male & $58(82.9 \%)$ & $15(21.4 \%)$ \\
\hline Female & $12(17.1 \%)$ & - \\
\hline Duration of abuse, years (SD) & $20.53(10.24)$ & - \\
\hline Alcohol units per week (SD) & $203.3(71.8)$ & - \\
\hline Alcohol type: beer & $21(30 \%)$ & - \\
\hline Alcohol type: wine & $25(35.7 \%)$ & - \\
\hline Alcohol type: Spirit & $24(34.2 \%)$ & $44(62.9 \%)$ \\
\hline Smoking & $58(82.9 \%)$ & $23.56(5.59)$ \\
\hline Total number of teeth & $21.24(6.53)$ & $1.97(1.69)$ \\
\hline Decayed; D (SD) & $2.15(1.65)$ & $6.04(4.59)^{*}$ \\
\hline Missing; M (SD) & $8.92(6.54)^{*}$ & $6.55(4.83)^{*}$ \\
\hline Filled; F (SD) & $3.33(2.59)^{*}$ & $13.44(4.48)$ \\
\hline DMFT (SD) & $14.40(6.08)$ & \\
\hline
\end{tabular}

${ }^{*} \mathrm{p}<0.05$ 
changes $\mathrm{pH}$ values, shifting them into the alkaline range due to the loss of carbon dioxide. A detailed explanation about establishing and registering salivary status was provided previously (16).

For registration purposes, the unstimulated saliva flow rates were categorized into 3 groups:
a) $<0.5 \mathrm{~mL} / \mathrm{min}$;
b) $0.5-1 \mathrm{~mL} / \mathrm{min}$; and
c) $>1 \mathrm{~mL} / \mathrm{min}$;

where no participant showed an unstimulated flow rate of over $1 \mathrm{~mL} / \mathrm{min}$.

The stimulated salivary flow levels were also categorized into 3 groups:
a) $<1 \mathrm{~mL} / \mathrm{min}$;
b) $1-2 \mathrm{~mL} / \mathrm{min}$;
c) $>2 \mathrm{~mL} / \mathrm{min}$.

The $\mathrm{pH}$ levels of the unstimulated and stimulated saliva were registered as follows:

(a) $\leq 4$; (b) 5 ; (c) 6 ; (d) 7 ; and (e) $\geq 8$.

\section{Data Analysis}

Descriptive statistics were used for data analysis. The data collected were analyzed using SPSS for Windows, Version 11 (SPSS, Chicago, USA). The between-group differences were tested using one-way and two-way variance analyses; an ad hoc test was used where needed. The correlation between nominal variables was determined using $\chi^{2}$ test $(\alpha=0.05)$, whereas the correlation between interval variables was determined using Pearson's correlation coefficient $(\alpha=0.01)$.

\section{RESULTS}

The demographic and behavioural characteristics of the study subjects are presented in Table 1. There was no difference in DMFT according to the type of alcoholic beverage typically ingested (beer, wine, or spirit) in the alcoholic group. DMFT was 14.40 in the test group and 13.44 in the control group (Table 1). Comparison of DMFT in both groups revealed no statistically significant difference $(p>0.05)$. The $\mathrm{D}$ and $\mathrm{M}$ components were greater in alcoholics than in the control group $(\mathrm{p}<0.05)$. There was a statistically significant negative correlation between alcoholism and the unstimulated salivary flow rate $(\mathrm{p}<0.05)$ (Table 2$)$. There was no significant correlation between alcoholism and stimulated salivary flow rate $(p>0.05)$ (Table 2$)$. The relationship of stimulated salivary flow on DMFT was not found to be statistically significant $(\mathrm{p}>0.05)$. Generally, the $\mathrm{pH}$ levels of the unstimulated saliva did not affect DMFT. The $\mathrm{pH}$ levels of the unstimulated saliva from the alcoholic group ranged from 5-7, whereas the $\mathrm{pH}$ ranged from 6-8 in the control group. Because the $\mathrm{pH}$ levels of most participants from both the alcoholic and the control group were within the range of 5-7 (60\% of the alcoholic group and $71 \%$ of the control group), a comparison was made within that $\mathrm{pH}$ range, yielding no statistically significant differences in terms of DMFT. The $\mathrm{pH}$ levels for unstimulated and stimulated saliva were significantly lower in the alcoholics group than in the control group $(\mathrm{p}<0.01)$. DMFT and $\mathrm{pH}$ levels of unstimulated saliva (at $\mathrm{pH}$ 6-7 and 7-8) were compared in the control group; there was no statistically significant difference $(\mathrm{p}>0.05)$. The $\mathrm{pH}$ level of the stimulated saliva did not significantly affect DMFT ( $\mathrm{p}>0.05)$. The $\mathrm{pH}$ measurements showed that $\mathrm{pH}$ levels of stimulated saliva from the control group were somewhat higher than the $\mathrm{pH}$ levels of saliva samples obtained from the alcoholic group. There was a statistically significant correlation between alcoholism and the $\mathrm{pH}$ value of stimulated saliva $(\mathrm{p}<0.01)$ (Table 2$)$. There was no correlation between the amount of alcohol units consumed and the number of carious lesions in a given patient $(\mathrm{p}>0.05)$.

\section{DISCUSSION}

Smoking and alcohol abuse were found to be related, with $82.9 \%$ of the subjects interviewed reporting both habits, which agrees with the previous findings (17). No major differences were found in the DMFT indexes for the alcoholics as compared to the control group. The missing $(\mathrm{M})$ component was higher, and the filled (F) component was lower, which was significant. In another study, alcohol abusers had DMFT of 17.79, while alcohol and drug abusers had DMFT of 15.67 (18). Among alcoholics, the M component was higher, and the D and F components were lower. It is possible that the "alcohol only" group had fewer decayed teeth due to the presence of fluoride in alcoholic drinks and/or the inhibitory effect of alcohol on cariogenic flora. Alcohol may also enhance the release of fluoride from certain restorative materials.

Table 2. $\mathrm{pH}$ and salivary flow rates of unstimulated and stimulated saliva among the study subjects

\begin{tabular}{|c|c|c|c|c|c|}
\hline & \multicolumn{5}{|c|}{ Flow rate } \\
\hline & \multicolumn{2}{|c|}{ Unstimulated [mL/min] } & \multicolumn{3}{|c|}{ Stimulated [mL/min] } \\
\hline & $<0.5$ & $0.5-1$ & $<1$ & $1-2$ & $>2$ \\
\hline Alcoholics & $63(90 \%)^{*}$ & $7(10 \%)^{*}$ & $23(32.86 \%)$ & $38(54.29 \%)$ & $9(12.86 \%)$ \\
\hline \multirow[t]{4}{*}{ Control } & $54(77 \%)^{*}$ & $16(23 \%)^{*}$ & $14(20 \%)$ & $48(68.57 \%)$ & $8(11.43 \%)$ \\
\hline & \multicolumn{5}{|c|}{$\mathrm{pH}$} \\
\hline & \multicolumn{2}{|c|}{ Unstimulated } & \multicolumn{3}{|c|}{ Stimulated } \\
\hline & pH 5-7 & $\mathrm{pH}>7$ & pH 5-7 & \multicolumn{2}{|c|}{$\mathrm{pH}>7$} \\
\hline Alcoholics & $67(96 \%)^{* *}$ & $3(4 \%)^{* *}$ & $62(88.57 \%)^{* *}$ & \multicolumn{2}{|c|}{$8(11.43 \%)^{* *}$} \\
\hline Control & $50(72 \%)^{* *}$ & $20(28 \%)^{* *}$ & $44(62.86 \%)^{\star *}$ & \multicolumn{2}{|c|}{$26(37.14 \%)^{* *}$} \\
\hline
\end{tabular}

${ }^{*} p<0.05,{ }^{* *} p<0.01$ 
These factors as well as the possibility that alcoholics probably sought and received dental care less frequently may explain why they had fewer filled teeth (18). The possibility that alcoholics have less dental care could explain low F component and high D and $\mathrm{M}$ components among alcoholics in our study.

Rooban et al. reported a mean DMFT of 3.31, 3.24, 4.09, and 2.89 for alcohol-only abusers, those who abused alcohol and chewed tobacco, and those who smoked tobacco and abused alcohol, and alcohol with smoking and chewing tobacco (19); the differences between the groups were statistically significant. The authors stated that changes in oral micro-flora owing to tobacco use and alcohol may play a critical role in the initiation and progression of dental caries. Other reports that evaluated the occurrence of caries in alcoholic individuals have reported conflicting results $(4,20)$. These variations may be due to factors such as the duration and type of alcohol abuse, sugar consumption, oral hygiene, smoking habits, and time since the last visit to the dentist. Alcoholics and substance abusers are known to have poor oral health. This may be the explanation for the higher number of missing teeth $(\mathrm{M})$ in our study, but there was no significant difference in DMFT or in the caries component (D) when the alcoholics and control individuals were compared. Signoretto et al. showed no significant differences in DMFT between the analysis subgroups (21). The lowest DMFT indexes $(6.8,7.65)$ were found in rare coffee and wine drinkers, respectively, while DMFT in non-users was 8.36. This negative result may be explained by the fact that the DMFT index takes the patient's entire dental history into consideration. Thus, caries and tooth loss may have occurred before the acquisition of healthy drinking habits. More detailed studies are needed on the identification of specific food components that play a role in oral health (21). Alcohol is currently considered as an independent risk factor for periodontal disease, and therefore, one can expect fewer teeth in those who drink alcohol (22). A case-control study of Finnish alcoholics revealed significantly fewer teeth and more remaining teeth with caries (10). This could be the result of psychological effects and personality changes in the abuser that may result in reduced interest in seeking and paying for dental care. The physiological effect of alcohol intoxication may lead to the inability to understand and accept advice given by healthcare workers, which would in turn lead to non-compliance. Less frequent dental care would explain why the alcoholics had fewer filled teeth.

Numerous reports indicate that the non-alcoholic ingredients in alcoholic beverages have an effect on dental caries (23-28). One study evaluated whether different drinking habits (coffee, tea, wine) could be related to differences in oral microflora. In vitro studies show that these beverages may retard bacterial adhesion (21). Cheynier showed a significant reduction in the mean number of general oral microorganisms as well as specific odontopathogens such as S. mutans and Lactobacilli in wine drinkers as compared to controls (29). It could be postulated that the consumption of these drinks may interfere with ability of oral bacteria to adhere to teeth in vivo, as previously shown by in vitro experiments. In conclusion, the ingredients from red and white wine could contribute to oral health by reducing the DMFT index. According to the above mentioned reports, certain components in wines and alcoholic beverages destroy or reduce oral pathogens. This could explain quite similar DMFT and D component among alcoholics and the control group in our study, but further research will be necessary to determine the validity of this hypothesis.

Alcohol consumption may also affect food habits and thereby affect dental caries. Carmonna-Torre et al. stated that wine may be superior to other alcoholic beverages in protecting against cardiovascular disease (30). The participants in our study were mainly from Slovenia, which is a Mediterranean country where most individuals consume a Mediterranean diet. Nonetheless, it was difficult to determine with certainty which type of alcoholic beverage the study population preferred. Although $35.7 \%$ of the alcoholics in this study preferred wine, alcoholics consume a variety of alcoholic beverages every day. According to previous reports $(21,23-28)$, there are some components in alcoholic beverages that have caries protective role, but it was therefore difficult to determine which beverage in particular, if any, protects against caries in our study. The data on alcohol type and quantity are based on the participants' self-reported information. The possible connections between alcohol and protection against caries are complex and should be investigated in futures studies.

Salivary flow rate and changes in $\mathrm{pH}$ may have influenced the DMFT index. The differences in saliva $\mathrm{pH}$ values are obviously caused by the differences in flow rates, as low flow rates result in low $\mathrm{pH}$ values. The results showed that the parotid and overall salivary flow rates were closely correlated to the intensity of the secretion-inducing stimulus applied (taste, chewing, or pilocarpine) (31). Notably, the bicarbonate $\left(\mathrm{HCO}_{3}\right)$ ion mediates saliva buffering and $\mathrm{pH}$ regulation and protects against dental caries and erosions (32). The highest mean saliva concentration of $\mathrm{HCO}_{3-}$ was found in stimulated saliva (31). The rate of stimulated salivary flow was similar in both groups, which may explain the lack of any significant difference in the DMFT index. The results from our study show that no significant association was found between unstimulated salivary flow rate and DMFT values.

This study has certain limitations. First, caries is a multifactorial disease with many etiological factors that were not investigated in this study (e.g., oral hygiene, sugar consumption, frequency of dental visits, risk factors, etc.). Each of these factors may affect the DMFT index. Second, the psychoactive drugs and medications used in alcohol dependency therapy (e.g., benzodiazepine) can affect the salivary flow rate. Such effects include a reduced salivary flow rate and dry mouth. Moreover, standard therapy for alcoholism in a psychiatric hospital takes approximately 8-12 weeks. This drug-induced period of decreased salivary flow rate may be too short to allow the development of caries or changes in the DMFT index among patients. Moreover, there is broad inter-individual variation in the prescribed doses of psychoactive drugs. Third, daily (non-alcoholic) fluid intake was not measured. This too may have affected the results. Finally, although saliva has been shown to play a significant role in the prevention of dental caries $(33,34)$, Hidas et al.found no evidence of reduced unstimulated salivary flow among alcoholics or any correlation with DMFT scores (35). However, a systematic review of 21 studies revealed a chronically low salivary flow rate $(<0.8-1.0$ $\mathrm{mL} / \mathrm{min}$ stimulated whole saliva) to be the strongest indicator of an increased risk for caries (36). The majority of the studies examined the relationship between caries on the crowns of permanent teeth and stimulated and/or unstimulated parotid and total saliva. It appears that neither the salivary stimulation status 
nor the method of salivary stimulation (that is, masticatory or gustatory) is important in the calculation of caries risk. There is insufficient evidence to establish any effect of either physiological saliva or pure secretions from the parotid, submandibular/ sublingual, or minor salivary glands on caries risk (36). There is only limited evidence that alcohol influences salivary secretion (37). Vitorino et al. reported that the $\mathrm{pH}$ difference between stimulated saliva unstimulated saliva is positively correlated with the DMFT index, but the results were inconclusive. The salivary test parameters used (singly or in combination) were not able to predict caries risk (38).

In conclusion, no differences were found with respect to overall DMFT in alcoholics and the control group. Alcoholism and stimulated salivary flow rate showed no correlation. Unstimulated salivary flow rate as well as the $\mathrm{pH}$ values of both unstimulated and stimulated saliva, were lower in the alcoholic group. The $\mathrm{pH}$ levels of the unstimulated saliva did not affect DMFT, but there was a statistically significant correlation between alcoholism and the $\mathrm{pH}$ value of stimulated saliva. To date, few reports have investigated the effect of excessive alcohol consumption on salivary flow and $\mathrm{pH}$ or the correlation with DMFT values. Our findings indicate that further research is required to understand this complex problem.

\section{REFERENCES}

1. Brickley MR, Shepherd JP. Alcohol abuse in dental patients. Br Dent J. 1990 Nov 24;169(10):329-31.

2. Rooban T, Rao A, Joshua E, Ranganathan K. Dental and oral health status in drug abusers in Chennai, India: a cross sectional study. J Oral Maxillofac Pathol. 2008;12(1):16-21.

3. Rooban T, Rao A, Joshua E, Ranganathan K. The prevalence of oral mucosal lesions in alcohol misusers in Chennai, south India. Indian J Dent Res. 2009 Jan-Mar;20(1):41-6.

4. Hornecker E, Muuss T, Ehrenreich H, Mausberg RF. A pilot study on the oral conditions of severely alcohol addicted persons. J Contemp Dent Pract. 2003 May 15;4(2):51-9.

5. Homann N, Tillonen J, Meurman JH, Rintamäki H, Lindqvist C, Rautio $\mathrm{M}$, et al. Increased salivary acetaldehyde levels in heavy drinkers and smokers: a microbiological approach to oral cavity cancer. Carcinogenesis. 2000 Apr;21(4):663-8.

6. Kurkivuori J, Salaspuro V, Kaihovaara P, Kari K, Rautemaa R, Grönroos $\mathrm{L}$, et al. Acetaldehyde production from ethanol by oral streptococci. Oral Oncol. 2007 Feb;43(2):181-6.

7. Warnakulasuriya S, Harris C, Gelbier S, Keating J, Peters T. Fluoride content of alcoholic beverages. Clin Chim Acta. 2002 Jun;320(1-2):1-4.

8. Abu-Bakr NH, Han L, Okamoto A, Iwaku M. Effect of alcoholic and low-pH soft drinks on fluoride release from compomer. J Esthet Dent. 2000;12(2):97-104.

9. Hede B. Determinants of oral health in a group of Danish alcoholics. Eur J Oral Sci. 1996 Aug;104(4 ( Pt 1)):403-8.

10. Enberg N, Wolf J, Ainamo A, Alho H, Heinälä P, Lenander-Lumikari M. Dental diseases and loss of teeth in a group of Finnish alcoholics: a radiological study. Acta Odontol Scand. 2001 Dec;59(6):341-7.

11. Proctor G, Shori DK, Watson RR, editors. The effects of ethanol on salivary glands. In: Preedy VR, editor. Alcohol and the gastrointestinal tract. Boca Raton: CRC Press; 1996. p. 111-22.

12. Scott J, Woods K, Baxter P. Salivary flow rate, protein and electrolyte concentrations in chronic alcoholic patients. J Biol Buccale. 1988 Dec;16(4):215-8.

13. Martin S, Pangborn RM. Human parotid secretion in response to ethyl alcohol. J Dent Res. 1971 Mar-Apr;50(2):485-90.

14. Enberg N, Alho H, Loimaranta V, Lenander-Lumikari M. Saliva flow rate, amylase activity, and protein and electrolyte concentrations in saliva after acute alcohol consumption. Oral Surg Oral Med Oral Pathol Oral Radiol Endod. 2001 Sep;92(3):292-8.
15. World Health Organization. Oral Health Surveys: basic methods. 4th ed. Geneva: WHO; 1997.

16. Dukić W, Dobrijević TT, Katunarić M, Milardović S, Segović S. Erosive lesions in patients with alcoholism. J Am Dent Assoc. 2010 Dec;141(12):1452-8.

17. Harris CK, Warnakulasuriya KA, Johnson NW, Gelbier S, Peters TJ. Oral health in alcohol misusers. Community Dent Health. 1996 Dec;13(4):199203.

18. Dasanayake AP, Warnakulasuriya S, Harris CK, Cooper DJ, Peters TJ, Gelbier S. Tooth decay in alcohol abusers compared to alcohol and drug abusers. Int J Dent. 2010;2010:786503. doi: 10.1155/2010/786503.

19. Rooban T, Vidya K, Joshua E, Rao A, Ranganathan S, Rao UK, et al. Tooth decay in alcohol and tobacco abusers. J Oral Maxillofac Pathol. 2011 Jan;15(1):14-21.

20. Novacek G, Plachetzky U, Pötzi R, Lentner S, Slavicek R, Gangl A, et al. Dental and periodontal disease in patients with cirrhosis - role of etiology of liver disease. J Hepatol. 1995 May;22(5):576-82.

21. Signoretto C, Burlacchini G, Bianchi F, Cavalleri G, Canepari P. Differences in microbiological composition of saliva and dental plaque in subjects with different drinking habits. New Microbiol. 2006 Oct;29(4):293302

22. Pitiphat W, Merchant AT, Rimm EB, Joshipura KJ. Alcohol consumption increases periodontitis risk. J Dent Res. 2003 Jul;82(7):509-13.

23. Daglia M, Papetti A, Grisoli P, Aceti C, Dacarro C, Gazzani G. Antibacterial activity of red and white wine against oral streptococci. J Agric Food Chem. 2007 Jun 27;55(13):5038-42.

24. Sugita-Konishi Y, Hara-Kudo Y, Iwamoto T, Kondo K. Wine has activity against entero-pathogenic bacteria in vitro but not in vivo. Biosci Biotechnol Biochem. 2001 Apr;65(4):954-7.

25. Dolara P, Arrigucci S, Cassetta MI, Fallani S, Novelli A. Inhibitory activity of diluted wine on bacterial growth: the secret of water purification in antiquity. Int J Antimicrob Agents. 2005 Oct;26(4):338-40.

26. Daglia M, Stauder M, Papetti A, Signoretto C, Giusto G, Canepari P, et al. Isolation of red wine components with anti-adhesion and anti-biofilm activity against Streptococcus mutans. Food Chem. 2010;119(3):1182-8.

27. Gazzani G, Daglia M, Papetti A. Food components with anticaries activity. Curr Opin Biotechnol. 2012 Apr;23(2):153-9.

28. Hannig C, Sorg J, Spitzmüller B, Hannig M, Al-Ahmad A. Polyphenolic beverages reduce initial bacterial adherence to enamel in situ. J Dent. 2009 Jul;37(7):560-6.

29. Cheynier V. Polyphenols in foods are more complex than often thought Am J Clin Nutr. 2005 Jan;81(1 Suppl):223S-229S.

30. Carmona-Torre Fde A, Garcia-Arellano A, Marques-Lopes I, Basora J, Corella D, Gómez-Gracia E, et al. Relationship of alcoholic beverage consumption to food habits in a Mediterranean population. Am J Health Promot. 2008 Sep-Oct;23(1):27-30.

31. Bardow A, Madsen J, Nauntofte B. The bicarbonate concentration in human saliva does not exceed the plasma level under normal physiological conditions. Clin Oral Investig. 2000 Dec;4(4):245-53.

32. Ericsson Y. Clinical investigations of the salivary buffering action. Acta Odontol Scand. 1959;17(2):131-65.

33. Stookey GK. The effect of saliva on dental caries. J Am Dent Assoc. 2008;139 Suppl 2:11S-7S.

34. Dawes C. Salivary flow patterns and the health of hard and soft ora tissues. J Am Dent Assoc. 2008;139 Suppl 2:18S-24S

35. Hidas A, Noy AF, Birman N, Shapira J, Matot I, Steinberg D, et al Oral health status, salivary flow rate and salivary quality in children, adolescents and young adults with ADHD. Arch Oral Biol. 2011 Oct;56(10):1137-41.

36. Leone CW, Oppenheim FG. Physical and chemical aspects of saliva as indicators of risk for dental caries in humans. J Dent Educ. 2001 Oct;65(10):1054-62.

37. Fenoll-Palomares C, Muñoz Montagud JV, Sanchiz V, Herreros B Hernández V, Mínguez M, et al. Unstimulated salivary flow rate, $\mathrm{pH}$ and buffer capacity of saliva in healthy volunteers. Rev Esp Enferm Dig. 2004 Nov;96(11):773-83.

38. Vitorino R, Calheiros-Lobo MJ, Duarte JA, Domingues P, Amado F. Salivary clinical data and dental caries susceptibility: is there a relationship? Bull Group Int Rech Sci Stomatol Odontol. 2006 Mar;47(1):27-33. 